\title{
NEWCOMER YOUTH: HOW INTEGRATION PITFALLS MAY LEAD TO PARTICIPATION IN ILLEGAL ACTIVITIES
}

\author{
By \\ Zainab Godwin, BA, UOIT, 2011 \\ A Major Research Paper \\ presented to Ryerson University \\ in partial fulfilment of the requirement for the degree of
}

\section{Master of Arts}

Immigration and Settlement Studies

Toronto, Ontario, Canada, 2017

CZainab Godwin 2017 


\title{
AUTHOR'S DECLARATION
}

I hereby declare that I am the sole author of this Major Research Paper. This is a true copy of the MRP, including any required final revisions, as accepted by my examiners.

I authorize Ryerson University to lend this MRP to other institutions or individuals for the purpose of scholarly research

I further authorize Ryerson University to reproduce this MRP by photocopying or by other means, in total or in part, at the request of other institutions or individuals for the purpose of scholarly research.

I understand that my MRP may be made electronically available to the public.

\author{
Zainab Godwin
}


Newcomer Youth: How Integration Pitfalls May Lead To Participation In Illegal Activities

\author{
Zainab Godwin
}

Master of Arts, 2017

Immigration and Settlement Studies

Ryerson University

\begin{abstract}
Newcomer youth's migration and integration experience is a topic with depths that are yet to be discovered. However, to enhance the integration experience, it is crucial that we look into the existing pathways and barriers to successful integration. Through a combination of primary research with 2 staff who work with newcomer youth in conflict with the law and 2 additional studies discussing integration barriers for newcomer youth, this study analyzes the systemic and individual barriers that may further marginalize newcomer youth and potentially result in their involvement in illegal/delinquent behaviours. Utilizing multiple theoretical frameworks, the research concludes that through gaps in the system (especially the education system), newcomer youth are vulnerable to illegal and delinquent behaviours as they settle and integrate in their new home country.
\end{abstract}

Keywords: Newcomer youth, barriers, settlement, integration, criminal justice system, delinquency, illegal activities. 


\section{Acknowledgements:}

I am very thankful to my supervisor Graham Hudson, for being a very encouraging and wellinformed support system throughout this process. Thank you for always affirming my thoughts and making me feel comfortable even when I sound like I may have lost it. Thank you for also guiding this research in a much better direction than where it was initially.

A heartfelt thank you to Grace-Edward Galabuzi. The first thank you is for your belief in me, three years ago when I allowed self-doubt to deter me from applying for the ISS program- thank you for telling me to go for it! And the second thank you is for helping me bring it full-circle by being my second reader. Your insight was perfect!

To my mom: “Momma, I did it!”. Thank you for your endless prayers, cooking for me and always encouraging me to keep pushing. You will forever be my inspiration. And to my dad, thank you for paving the way- one more degree and I will be at your level.

To my partner, my fiancé, my best friend: I am so grateful for your continuous encouragement, the celebrations every time I hit a milestone and (annoyingly) reminding me of deadlines. Thank you for understanding when I have to miss out on outings because of school.

To my friends and family: I am so blessed to have you all in my corner, rooting for me and letting me know you support me. These past two years have only served as a reminder of how fortunate I am to have you all in my life. Love you all! 


\section{Table of Contents}

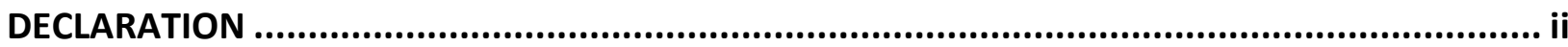

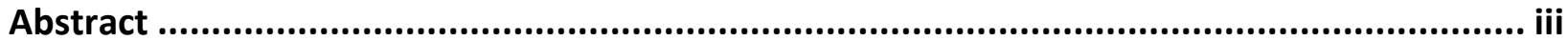

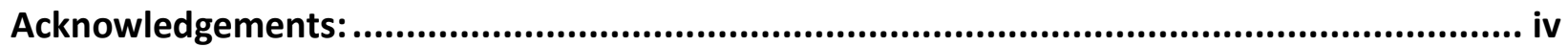

Bibliographic Context: ..................................................................................... 1

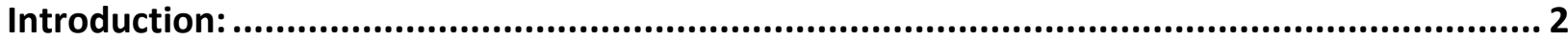

Literature review:

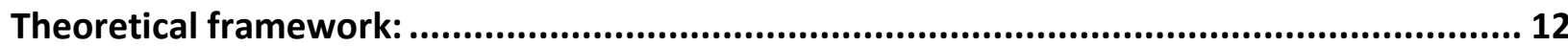

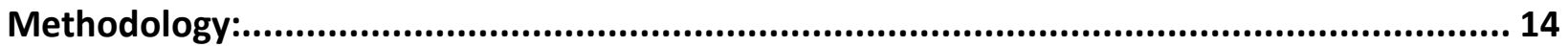

Defining and understanding integration and settlement: ............................................. 17

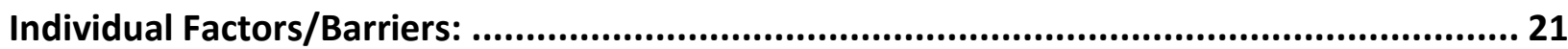

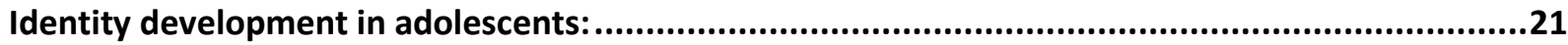

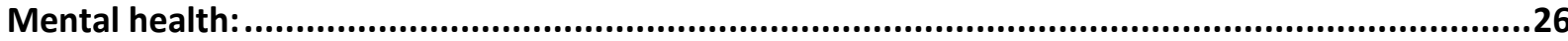

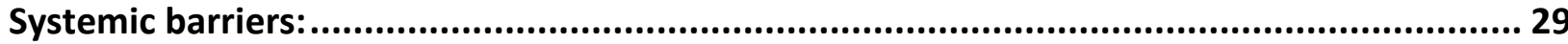

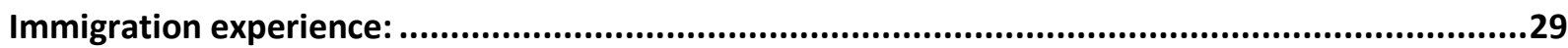

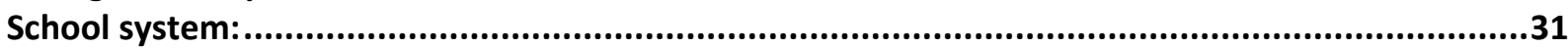

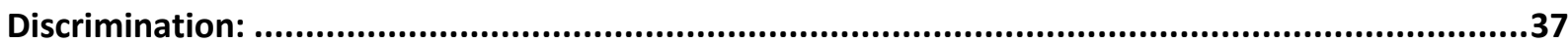

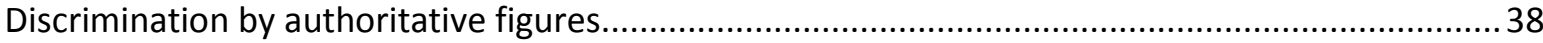

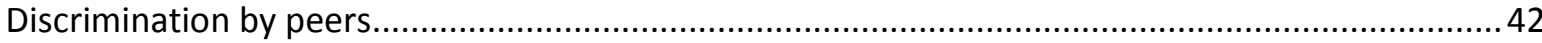

Newcomer youth- delinquency and illegal activities: ................................................... 47

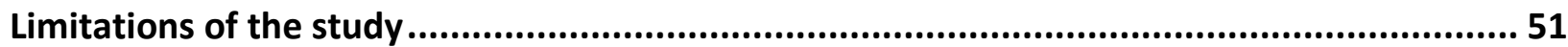

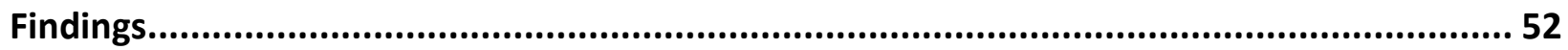

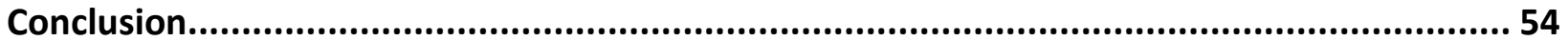

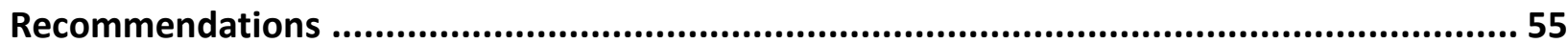

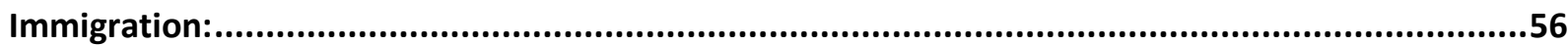

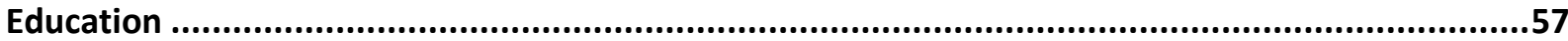

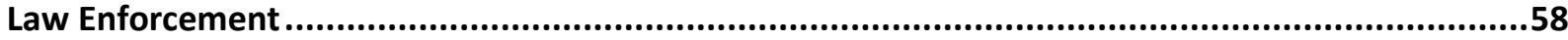

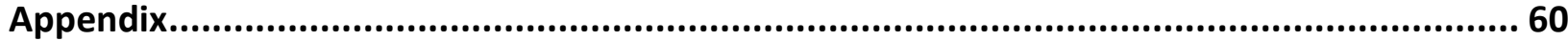

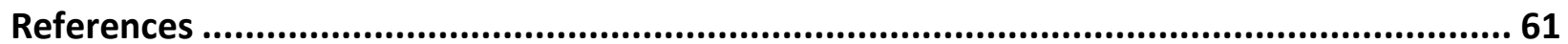




\section{Bibliographic Context:}

My interest in this topic was brought about through my experience working with youth in the criminal justice system. Through my work with this population and assessing the data collected over the last 3 years, I noted an increasing presence of newcomer youth being referred from the courts for community based support. Further assessment revealed that many of them have had more than one encounter with the law- a large number of them had a second charge of breach of probation. As my interest piqued, I decided to conduct a research study to understand the different reasons newcomer youth offend as well as factors that influence their actions towards illegal activities. I was then faced with the harsh reality that this is not a subject that is commonly discussed in the academic world; irrespective of how important it is.

After speaking with colleagues at other organizations who serve a similar population and getting confirmation that this is a phenomenon we are all experiencing, I wanted to change the state of limited research on this population. As a firm believer in the fact that only those who have the experience can speak on it, I applied for funding to conduct a community based Participatory Action Research with newcomer and first generation Canadian youth who have been involved in illegal activities. This research provided a safe space for newcomer and first generation Canadian youth to express the barriers they have encountered that further marginalized them and acted as stimulus to committing offences. Upon completion of that research, it only seemed right that I continued to look into the issue further. And as a student in the process of completing her masters in Immigration and settlement studies, I could not have selected a better topic to add insight to. 


\section{Introduction:}

Newcomer youth experience a big life change when moving to a new country - at a very formative period of their lives. Although social services and programs have traditionally been divided into children and adult services, there is growing recognition that young people's needs are distinct from both children and adults, and youth-specific programs are increasingly common (AMSSA, 2016). The rights and interests of "newcomer youth" has gained recognition as an important topic in recent years. The limited research on the experiences of newcomer youth in Canada almost always features a line or two from the researchers about the scarcity of previous research on this population. Chuang et al (2010) references this gap in stating that these stresses of adjusting and settling in a new country that youth experience, especially their coping strategies, have received limited attention. Given the importance of this topic, more work must be done in this area. In comparison to other immigrant groups such as newcomer children, newcomer women, immigrant workers, refugees, etc., the research available on newcomer youth alone is still rare.

Historically, Canadian immigration discourse has been dominated by the economic contribution of migrants; especially those who are able to enter the labour market immediately. Much previous research involving children's social inclusion and exclusion has mainly focused on adult centered approach with children recognized as passive recipients of economic and social resources of their parents (Oxman-Martinez, et al, 2014). While this neoliberlist rationale of focusing on parents and working age migrants can be understood for the immediate positive effect it offers, I wish to problematize the rationale and argue that for long-term gain, youth have 
a higher potential to contribute to the economy both for a longer period of time and potentially in a higher financial bracket that a Canadian education will award them.

The lack of information on newcomer youth is also linked with the prevailing assumption that "few youth experience long-term adjustment problems in school and in the labor market when compared to adults" (Wilkinson et al, 2013). It is certainly reasonable to assume that young people are usually able to get acquainted to a new environment easily. Despite the assumption of newcomer youth's ability to integrate easily, the fact remains that there is a significant number of newcomer youth who have a hard time integrating and find themselves on the outskirts and often breaking the law. Thus, their challenges should not to be taken for granted.

According to the first data from the 2011 NHS, Canada had a total of about $6,775,800$ foreignborn individuals who arrived as immigrants. They represented $20.6 \%$ of the total population, compared with $19.8 \%$ in the 2006 Census, and an estimated $34 \%$ of the newcomer population in Canada is under the age of 25 (Stats Can, 2011). That is a significantly large percentage of newcomers to exist in a state of limited information.

As the young population lead the way for a "new" Canada, it becomes imperative for researchers, service providers, and social policymakers to investigate the multiple challenges and barriers that newcomer youth face as they navigate through their adjustment and settlement processes. Although the cultural patterns of Canada have changed over the years, there remains a paucity of research on how newcomer youth adjust and settle into their new homeland. (Chuang et al, 2010). It is essential to understand the different stages newcomer youth are in at the time of migration- as it relates to age and growth- in order to ensure that integration programs and 
services that are provided are able to consider and accommodate the challenges they may encounter based on their age, gender, country/region of origin, race, demography of their new community, etc.

In the discourse of newcomer youth's successful integration, the onus is often placed on the school system as it is where majority of a young person's time is spent. Schools are essential not only for the education of this age group of newcomers, but as a critical location for services to help their integration (CERIS (2000). ... an indication of how well immigrant students are integrating into their new community is whether, and to what extent, they feel they belong to their new surroundings - and, for 15-year-olds, one of the most important social environments is school (OECD, 2015). This creates an expectation that the school system will make provisions to ensure that their diverse needs are met, and that they will be supported to integrate seamlessly. The psychological wellbeing of immigrant students is affected not only by differences between their country of origin and country of destination, but also by how well the schools and local communities in their country of destination help them to overcome the myriad obstacles they face in succeeding at school and building a new life (OECD, 2015).

The diverse needs of newcomer youth, especially racialized newcomer youth, plays an important role in identifying integration strategies and approaches that should be adopted or considered by institutions, policies and individuals who play a major role in the settlement and integration of newcomer youth. The risk factors that pose a threat to the successful integration of newcomer youth must be identified in order for solutions and strategies to be developed. 
The purpose of this research paper is to clearly outline the impact a failed integration for a newcomer youth has on the individual and the community at large. This paper will discuss the barriers newcomer youth encounter that hinder their successful integration and attempt to connect the reacting behaviours to potentially leading them to gang and criminal activities. This research does not intend to claim that newcomer youth will offend or that they offend more than their Canadian born counterpart. Rather, it aims to shed light on some barriers that have been identified by researchers (Rossiter et Rossiter, 2009; Chuang et al, 2010; Godwin, 2017) as having particularly affected the way newcomer youth settle in Canada. Furthermore, it will directly link these barriers to contributing factors of newcomer youths' potential involvement in criminal activities. The paper aims to answer the questions of 1) what systemic and individual barriers do newcomer youth repeatedly encounter?; 2) how is their integration experience affected by these barriers?; 3) of those who are involved in the criminal justice system, what barriers do they cite as a contributing factor?

As the term youth can have many different characteristics that define it, especially within the different institutions and spaces that will be discussed throughout this paper, I find it essential to clearly outline how it will be used in this paper. For the purpose of this paper, newcomer youth refers to individuals who migrated to Canada over the age of 12 and under the age of 21 . Integration and settlement will be used interchangeably to refer to the process through which newcomer youth become accustomed to life in Canada.

\section{Literature review:}

Within the last decade, discourse around newcomer youths' settlement and integration has gained a slight momentum, however, there is still a lot more grounds to cover. In order to 
articulate the gap that my study aims to cover, it is imperative that I conduct a thorough review of existing literature that is relevant to this topic. My review focused on studies that assessed the settlement and integration needs of newcomer youth and the implications a less than ideal integration has on their well-being.

Chuang et al (2010) examined the settlement pathways of newcomer youth in Canada and how this experience shapes the daily lives of youth. Chuang's study acknowledged the vulnerability of adolescent youth and how additional stressors such as relocating, especially to a new country, can intensify the struggle they experience. Chuang's study was conducted on 125 newcomer youth between the ages of 11-20, residing in 5 provinces of Canada and had permanent resident status. The first part of the study identified the top 3 settlement challenges using a questionnaire and the second part consisted of a focus group. Of the challenges identified, $74 \%$ of youth respondents stated language barriers and acquisition as their greatest challenge and peer relations as their second greatest challenge. They noted additional challenges such as school issues, Canadian environment, Canadian culture, financial issues, and negative behaviours, parent-child relations, missing native country, balancing dual cultures and preferring native culture as their top challenges.

Additionally, the study participants individually identified their coping strategies to include books, TV, and media, general personal characteristics, practicing their skills, relying on their culture, choosing friends, ignoring negative behaviours, being realistic/patient. As a group, they identified teachers and schools, friends/peer support, community resources, and family support as part of their coping strategies. Chuang echoes the call of service providers, school administrators, and social science researchers for Canada to pay attention to and do more in 
supporting the integration needs of newcomer and refugee youth. Limitations with this study in regards to its use in my research is that the participants appear to be newcomer youth who have had success with their coping strategies- they do not identify as having experience delinquency. Nonetheless, the challenges they outlined are extremely relevant to this research.

Caxaj et al (2010) examines the notion of 'belonging' among newcomer youth. Although this research exists solely to provide a link between newcomer youths' sense of belonging and their health and wellbeing, it also serves as a great source to better understand the impact that social exclusion has on youth in general, and more specifically on newcomer youth. The research highlights that intersecting positions such as gender, "race," and class, in combination with limited knowledge of the dominant language and experiences of war, complicate social negotiations toward belonging among newcomer youths (Caxaj et al, 2010). The coupling of past violence experiences and present-day discrimination on any grounds is shown to have an adverse effect of the integration of newcomer youth- their seamless resettlement is jeopardized as a result. Overall, the study identified the following 6 areas of struggle in constructing a sense of belonging for newcomer youth: (1) feelings of difference and unfamiliarity; (2) the role of the family; (3) life left behind/feelings of loss; (4) new opportunities and challenges; (5) navigating public and private spaces; and (6) deconstructing identity, enacting diversity (Caxaj et al, 2010). For newcomer youth, the difference in something as minute as the way homes are built in Canada can increase their sense of isolation. "For some, who had come from more close-knit communities, distant neighbors exacerbated feelings of isolation (Caxaj et al, 2010). This feeling is further exacerbated through marginalization based on race, gender, religion and other differing factors. The research also sheds light on the fact that newcomer youth experience migration differently from younger children. Unlike younger children, they have strong memories of their 
formative years in another place and being removed from that familiar place creates a sense of loss and nostalgia. As a response to the pressure to conform and assimilate to an identity that matches their new home country, newcomer youth in this study chose a path of deconstructing identity and enforcing the acknowledgement of their diversity.

Quirke (2011) explores the settlement experiences and information practices of Afghan Newcomer youth in Toronto. Quirke's study covers a gap in immigration research by documenting the context of settlement for Afghan newcomer youth in Toronto. The study provides insight in general newcomer youth settlement issues as well as providing a detailed explanation of integration and settlement. The challenges are significant, as young immigrants and refugees arriving in Canada must learn English or French, navigate a new school system, deal with separation from family members and friends left behind in their country of origin, cope with the stress of adapting to different roles shaped by shifting family dynamics, balance the sometimes conflicting values of family and peers, and grapple with issues of identity formation and the pressures of adolescence (Quirke, 2011).

Anisef et al (2003)'s managing Two Worlds identifies and examines a range of challenges and needs encountered by immigrant youth as they make the transition to life in Canada, exploring issues that include personal adaptation to a new culture; coping with a new and often different school environment; adjusting to changed family dynamics that accompany immigration; and finding employment in a new country. In order to determine the types of programs and services that are beneficial to immigrant youth in responding to these types of issues, it is important to identify and catalogue the diverse needs among youth of different ethno cultural backgrounds (Anisef et al, 2003). The research draws attention to the delicate stage of adolescence that 
newcomer youth are in, while experiencing this life changing moment of migration.

Additionally, the research discusses the low socio-economic status of most immigrant families, especially as it relates to the health and well-being of immigrant youth and children.

Godwin (2017)'s report on a Participatory Action Research conducted with newcomer youth in the Toronto region who have had encounters with the law provides strength to the argument of systemic barriers influencing newcomer youths' path to illegal activities. With the limited qualitative research available on newcomer youth and their involvement in the criminal justice system, this report is timely and very valuable to the discourse. The study featured 15 newcomer and first generation Canadian youth between the ages of 15-21 who migrated to Canada within the last 5 years. The youth participated in this study as co-researchers as well as study subjects. The objective of the study was to understand first-hand the systemic barriers that newcomer youth identify as having played a role in their involvement in illegal activities.

Through in-session conversations/focus group, the participants identified the lack of information during immigration, law enforcement, and an array of issues within the education system and barriers that played a significant role in their involvement in illegal activities. The participants also conducted surveys on other newcomer youth to assess the scale at which these issues affect the larger newcomer youth population. The study found that newcomer youth's experiences are very different from their adult counterparts and should looked into further by policy developers. Specifically, the study outlined that racism, discrimination and lack of support within the education system, compounded with other individual barriers adolescents encounter at that stage, creating the ideal recipe for newcomer youth to be further marginalized and eventually fall between the cracks and get lost in the system. 
Overall, most researchers have consistently outlined that the issues newcomer youth encounter during their integration process are often complex. The needs of newcomer youth differ greatly from the needs of adult newcomers. Youth between the ages of 12-18 (newcomers and Canadian born) are very diverse and their needs and interests change at a very rapid stage. As highlighted by Chuang (2010), for adolescents, individuals undergo significant developmental transitions and changes (e.g., puberty, increased levels of independence) during this particular period of life. Psychological stresses are created by settlement challenges and barriers, and the ways in which individuals cope with these circumstances are central concepts for understanding newcomer youth. It is thus imperative that settlement structures and processes are designed with consideration of an in-depth understanding of the traditions, learning aptitudes, family structures and moral values of immigrant and refugee youth to successfully meet their educational needs (Anisef, 2005). The results of Anisef et al's 2004 study strongly indicate that the needs of newcomers aged 16 to 20 are simply not being met. They seem in some kind of integration limbo: not old enough to be aided by programs for newcomer adults, not young enough for adjustment to be the gradual, family mediated process that it can be for much younger children, nor even young enough to have the time necessary to adjust before graduating from high school (Anisef et al, 2004).

However, recurring themes noted in the limited literature available on the challenges newcomer youth encounter during integration include barriers within educational institutions, limited information during the immigration process and identity development. Chuang et al (2010)'s study and Godwin (2017)'s participatory action research both report school issues and balancing dual cultures as part of their top barriers. 
In relating newcomer youths' integration and settlement struggles with their presence in gangs and the criminal justice system, it would be detrimental to my if I had failed to review Although slightly outdated, Rossiter \& Rossiter (2009)'s study on Immigrant youth and crime provides a great foundation to continue building the case that certain encounters that may not be unique to newcomer youth impacts this population differently. This research connects Abraham Maslow's hierarchy of needs to newcomer youth's successful integration to their new home country and highlights that in addition to meeting these basic needs, newcomer youth must also develop linguistic and cultural competence in order to succeed. While all youth/adolescent experience the process of meeting the hierarchy of needs, newcomer youth experience it differently and this additional stressor, if no support is present to alleviate it will have a negative effect. The study attempts to understand the crimes that are committed by immigrant youth, the factors that influence their gang and/or criminal involvement as well as factors that hold a positive influence on them. To achieve this, 12 community stakeholders were interviewed. They noted highlighted family risk factors, school risk factors, community risk factors as having detrimental effects to the successful integration of newcomer youth. The research also looked into protective factors and listed family dynamics to have a positive effect along with individual protective factors, peer protective factors, school protective factors and community protective factors. However, these factors fall on either the protective side or the risk side depending on the multiple factors. For example, family is listed as both a risk and protective factor; under risk factor, negligence of youths' well-being by parents who must focus on working to make ends meet generally leaves the youth feeling isolated and increases their risk of involvement in gang and criminal behaviours. Alternatively, in families where youth are fully supported and given 
attention, they are positively influenced and feel secure, thus decreasing the potential for risky behaviours.

While the aforementioned research has paved the way for my research, I must echo these researchers' sentiments that there still remains much grounds to cover in the discourse of newcomer youth's settlement experiences. Accordingly, my research aims to provide connectivity between previous research and new information on newcomer youth and their pathways to gang and criminal activity.

\section{Theoretical framework:}

Selecting one theoretical perspective to understand the complexity of newcomer youth's integration is a difficult task at this stage. As more research is uncovered in this area, the task of selecting a theoretical explanation would become easier. However, there are many theories that can be applied and there is room for future research to delve further into each theory on this topic.

Functionalist theory focuses on the macro-level of social structure, rather than the micro level of everyday life. This theory is very relevant to the discourse around how youth (and all newcomers) integrate as it discusses how each part of society contributes to the stability of the whole society. Durkhiem explains that society is made up of fragments and each of these fragments must play their part in ensuring that society functions accordingly. For integration to be successful, both the newcomer and the host (country and its residents), must play an equal role for a successful integration to take place. But integration is a two-way street: it entails the 
willingness of new Canadians to embrace their new home and — equally significantly — the willingness of the wider society to lower the barriers to their becoming active and productive members of their adopted home (Berns-McGown, 2013). When one part of this equation fails to play the necessary role, the presence of disruption to society is inevitable. In this case, when newcomer youth faced with discrimination and unwelcoming situations, their integration process is disrupted and they in-turn are unable to fully integrate as law abiding citizens.

Social learning theory is strongly relevant to this topic as it looks at the individual learning process through which people develop their self identity and the influence society has on socializing individuals. Through this theory, we are able to assess the ways newcomer youth (and all adolescents) develop their sense of identity and the role that society plays in that development. According to this theory, behaviors and attitudes develop in response to reinforcement and encouragement from the people around us and is often used in reference to deviant and criminal behaviours.

Social learning theory specifies the general social, emotional and cognitive learning mechanisms by which the rationalizations, norms, rules, and motivations of behavior are learned and perpetuated (Bishop et al, 2017). Similarly to functionalist theory, it places partial responsibility on society for the development of one's self. To apply this theory as an explanation to the hypothesis that the integration process plays a role in newcomer youth's potential involvement in criminal activities would be accurate, although not entirely sufficient. Social learning theory informs the social development model by identifying which patterns of behavior are adopted, reinforced, and discouraged and the mechanisms by which these patterns occur. Specifically, ...if prosocial interactions and involvement are experienced as rewarding, they reinforce the development of bonds to prosocial others and commitment to prosocial lines of action. 
Alternatively, if involvement and interactions with those engaged in antisocial behaviors are experienced as rewarding, they reinforce the development of bonds to antisocial others and perceptions that antisocial behavior will be rewarded (Bishop et al, 2017). If newcomer youth are welcomed and their positive behaviours are rewarded, according to this theory, they will most likely continue to behave in a positive manner. Alternatively, if they find solace in a crowd that encourages and accepts their negative behaviour, they will be socialized to continue on this path.

Differential association theory can also be applied to this topic. It states that delinquency is learned through interactions with others in a process of communication within intimate social groups. Under differential association theory, delinquency results from the cumulative exposure to individuals who engage in violations of the law relative to those who do not (Bishop et al, 2017). Similar to social learning theory, differential association provides an explanation for how individuals can be socialized into certain types of behaviours. Peers often have the most influence over the behavior of adolescents as they spend large amounts of time together in the social environment of the school (Tolle, 2017). To apply this theory to this topic would once again be accurate as the implications are that newcomer youth are socialized by negative influences into negative behaviours.

\section{Methodology:}

The intention of this research paper is to identify barriers that newcomer youth encounter through their migration and integration experience that could increase their potential to be involved in gang or criminal activities. To attain this, a lengthy review of the literature available 
on newcomer youth, especially newcomer youth in the criminal justice system was conducted, along with interviews of staff who support newcomer youth in the criminal justice system for supporting information. For the interviews, as they were with human subjects, an ethics approval was required. This part of the research was conducted in accordance with Ryerson University's Research Ethics Boards' guidelines.

In order to provide a complete picture of how newcomer youth go from immigration and integration to gangs and incarceration, I have conducted a thorough review of Chuang et al (2010)'s examination of the settlement pathways of newcomer youth, an analysis of a Participatory Action Research on newcomer youth's integration to incarceration and finally an interview with service providers who support newcomer youth in conflict with the law.

To enhance the information previously published on this issue, I used data from Godwin's (2017) Participatory Action Research (PAR) on newcomer youth in the criminal justice system. The PAR included information from 15 co-researchers who were between the ages 15-21. The surveys conducted for the research includes information from 44 youth who identified as newcomers, having migrated to Canada between middle school and high-school. The researchers and research participants identified the school system, family issues and peer influence as some of their greatest challenges to integration and influencers to participate in illegal activities.

To support the information provided in the research report and to seek additional information, I opted to conduct individual interviews with adults who work with newcomer youth in conflict with the law who can expertly speak on the barriers they have identified with the newcomer youth. The interview was conducted with 2 Social Workers who provide wrap-around support to 
youth in the criminal justice system within the Toronto region. Having some familiarity with the organization I outreached was advantageous for me and made it very easy to recruit participants. I visited the organization and dropped off a flyer instructing qualified and interested staff to contact me via e-mail/phone. Once contacted by the staff, I provided a brief overview of the study and verbally confirmed their interest to proceed with the interview. During the phone call with the participants, I asked qualifying questions to confirm that they are the ideal candidate(s). I asked questions about the population of youth they work with and the length of time they have worked with this population. Through this method, I was able to select to 2 participants who had the most experience working with newcomer youth in conflict with the law. I proceeded to send a copy of the consent form to the participants for review before we met for the interview. I conducted the interviews with a male staff and a female staff from the same non-profit youth focused organization, using a recording device and taking notes electronically. The recorded interview was later transcribed verbatim and to ensure accuracy of statements, the transcribed interviews were sent to participants to review and confirm their responses. The notes were also cross-checked with the transcribed interviews for accuracy.

Interview participants were asked to give their expert knowledge on the barriers newcomer youth face that propels them into gang and criminal activities. They were asked questions about common themes that they have uncovered that start the journey to gang and/or criminal activities for newcomer youth. They were also asked questions about specific institutions like schools and the role they play in propelling newcomer youth into gang/criminal activities. The questions were constructed to provide additional information and confirm the roles certain institutions play in shaping the integration experiences of newcomer youth. All questions asked are noted in the appendix section. 
These 3 sources have been compared for common themes on factors that propel newcomer youth into gang and criminal activities. The themes that emerged can be categorized broadly as systemic barriers and individual factors. Systemic barriers are barriers that are created by a body of power through policies and or practices that prevents fair access to opportunities for some and not others. These include discrimination within the school system, profiling by police officers, lack of recognition of immigrants' foreign attained credentials, etc. Individual factors or personal barriers refer to factors that are uniquely experienced by a person and not enforced by an external party. Examples of individual barriers newcomer youth encounter include feeling of nostalgia towards their home country, mental health issues, self-esteem issues, etc.

This research paper will pull from the 3 main sources to gain a clearer understanding of how newcomer youth are propelled into gangs and criminal activities through systemic and individual barriers. Additionally, the paper will conclude with recommendations for adequate support services to successfully integrate newcomer youth and avoid gang and criminal activities.

\section{Defining and understanding integration and settlement:}

According to Statistics Canada, in 2011, 20.6\% of Canada's population was foreign-born and $33.7 \%$ of that population are youth (Stats Can, 2011). This number makes up a large portion of newcomer migration with a greater potential to spend their lives contributing to the Canadian economy in the long run. It is therefore extremely problematic that “... the settlement needs of youth in Canada are often overlooked by immigration research and policies, which focuses 
instead on the economic integration of adults" (Quirke, 2011). Integrating immigrants and their children into the labor market and society as a whole is vital for promoting social cohesion and economic growth of host countries and the ability of migrants to become self-reliant, productive citizens (OECD, 2015). Additionally, since 1974, Canada established an Immigrant Settlement and Adaptation Program which offered services to facilitate the adaptation, settlement and integration of newcomers to Canada in order for them to participate to the best of their ability in the Canadian economy (CIC, 2011). This was later transformed in 2007 into a full-fledged program by 2010. This new program is now called the Canadian Immigrant Integration Program and it provides free pre-departure orientation to Federal Skilled Workers, Provincial Nominees, and their spouses and adult dependents, prior to migrating to Canada. This new program is an ideal endeavor and would answer a lot of questions that may fuel conflict in the integration process, post migration. However, this endeavor is lacking a very important piece; it neglects the needs of school aged dependents. Immigrant youth are an after-thought in terms of their successful integration in Canada.

The effective integration of migrants is not an economic and labour-market process alone. It also has social, educational - even spatial - facets. None, though, are mutually exclusive: disadvantage and the failure to integrate in one dimension are likely to have multiple repercussions (OECD, 2015). "Integration is a term that refers to the process by which, over time, immigrants become a part of the host society. It is a normative concept and therefore one whose meaning can vary among immigrant-receiving societies. Though originally conceived as a one-way adaptation by which immigrants assimilated into the mainstream of receiving societies, integration has come to mean the two-way shift through which both the immigrant and 
the institutions of the host society adapt as a result of their exposure to one another across generations following migration" (Quirke, 2011).

Immigrant youth come to Canada with enormous potential to make a significant, positive contribution to the future of their adopted country. In many cases, this potential is realized; in others, it is not. The ease with which immigrant youth and their families integrate into Canadian society has a strong impact on their futures; those who become marginalized during this process risk becoming alienated or involved with the criminal justice system (Rossiter \& Rossiter, 2009). To minimize this risk, attention should be paid to the ways newcomer youth integrate and settle in Canada.

The most prominent definition or model of settlement in Canadian immigration literature outlines three stages of adjustment following migration in terms of the needs for services that occur at each stage. In the initial settlement stage, immediately following arrival, newcomers may need translation and interpretation services, language instruction, and reception and orientation services. In the intermediate stage, access to institutions and programs is needed to develop employment-related skills, bridge cultural differences, and facilitate labour-market integration. Other needs during this stage include health services, housing, employment-related language training, and legal assistance. The final stage of settlement is the long-term struggle for equal participation in all realms of life, politically, socially, economically and culturally (Quirke, 2011).

To get a better understanding of how newcomer youths' integration is perceived by those who work closely with them, interview participants in this research were asked their opinion on 
whether newcomer youth integrate easily or not. Both interview subjects expressed that they do not believe that newcomer youth integrate easily into Canada, despite a pre-existing popular belief that with schools and the ability to make friends, they will feel like Canadians in no time. One respondent stated that they "think newcomer youth have the hardest time settling into a new country. They are so fragile and unsure of themselves and just looking for someone to direct them. They have so much potential but get stuck in this rump of figuring out who they are and how they fit into this new world".

Additionally, youth in Chuang's study highlighted language barriers as their top challenge to settling into Canada. As language is a necessary part of social interactions, it is easy to see how the inability to use it comfortable poses a threat to the success integration of newcomer youth. Often, it is not that these students are not able to speak or write in English and French, it is more so the discomfort of using everyday conversational words and slangs that they are unfamiliar with. This challenge will be elaborated on as the research paper progresses.

Noteworthy, when asked about challenges they face settling into Canada, youth in Chuang's study did not list their age and identify development as a challenge. This highlights the importance of assessing these challenges from multiple perspectives and lenses; in this case, from the perspective of the youth and that of their adult allies.

The barriers to successful integration that are encountered by newcomer youth are unique and depending on several variables (including their experiences prior to migration), they will react differently to these barriers. Some of the commonly reported barriers encountered by newcomer 
youth can be categorized as individual barriers and systemic barriers. The following sections will discuss these two categories in more details.

\section{Individual Factors/Barriers:}

Each immigrant arrives in Canada with a story of their own and an experience that influences the way they see the world and understand things. Journeying to a host country can have very different experiences for youth compared to their adult counterparts (Thomas, 2012).

There are a number of individual barriers that newcomer youth battle with that makes their integration a challenging one without the addition of external/systemic barriers. These may not be the experiences of all newcomer youth as no 2 youth are the same

\section{Identity development in adolescents:}

Adolescence is a particularly vulnerable period of time as individuals undergo significant developmental transitions (e.g., physiological and emotional changes, increased desires for independence). With these prevalent adolescent challenges, newcomer youth must deal with additional challenges such as negotiating their lives within various multicultural environments and cultures (e.g., family, school, and community). However, these stresses of adjusting and settling in a new country that youth experience, especially their coping strategies, have received limited attention (Chuang et al, 2010).

In addition to facing the usual and highly intensive developmental issues specific for adolescence at a time typically associated with the difficult process of growth and independence, immigrant 
and refugee newcomer youth must also start a new socialization process. They must meet new academic challenges; learn new expectations from their schools, teachers, and parents; gain acceptance into new peer groups; and develop new kinds of social competence (Anisef et al, 2003).

The establishment of friendships is fundamental to positive youth identity development (Cooper, 2008). As adolescents work towards understanding who they are as an individual and against the backdrop of society, social inclusion and belonging is an important part of their identity development. Youth with close friends demonstrate better academic performance, lower rates of criminal involvement, and lower school dropout rates, compared with those who do not have friends as sources of intimacy and social support. Young people who are not socially wellintegrated or who have negative peer influences report that they are less satisfied with their lives, less happy with their home lives, less likely to enjoy school or feel that they belong at school, and more likely to feel lonely and left out (Cooper, 2008).

One of the interview participants mentioned that they have repeatedly heard newcomer youth who are in conflict with the law mention that they had a very hard time making friends and the friends that they did make were not particularly model citizens.

"Oh, they struggle big time! So many of them told me that they had a really hard time making new friends. Many other students did not want to be friends with them because they already had their friends or they just don't want to be friends with the new kid. But even the kids themselves don't even know how to begin looking for friends. They still have to figure out what they like and what 
they don' like. But they spend so much time trying to understand things in this new place, and feeling alone and then they end up making friends with the wrong people because those people accepted them when they were most vulnerable".

Interview Participant

For newcomers, being the "new kid" was a difficult part of their new lives. As described by one youth (18-year-old Chinese Ontario girl), "Because they're already a group. They know each other so they don't really want you to become a new member in that group." Thus, some youth found it very difficult to break into the existing establishment of groups (Chuang et al, 2010).

As newcomer youth try to identify themselves in this period of development, within a new country where their identity is not readily available to them, they find themselves pulled in many different directions. The Rising Researchers -in a discussion about discovering who they are and making friends- expressed that it is really difficult to figure it out. They find it overwhelming to live up to the standards their families have for them while trying to fit in with their peers. They don't think their parents will understand what they have to deal with and "there is no one at school to talk to" A Rising Research. Many of the participants attested to doing things their friends were doing just so they would fit in and not feel like they are weird.

Once newcomer youth start to feel like they are getting a hang of this new country, they generally soon discover that some things that are normalized and acceptable here are not treated the same by their families. "Many of them get comfortable and start to do things that are okay in Canada, but then their parents are like nope! Not in my house. But they always think that if they 
don't act like the Canadian kids, they will lose their friends. And the fear of going back to being lonely pushes them to keep acting like the Canadian kids. And at home, they do what their parents want. So, it's a constant battle for them".

At the intersection of systemic and individual barriers, we encounter the experiences of most racialized or ethnic youth who come from a very rigorous cultural background with strict practices and expectations that are generally different from the culture of mainstream Canada. They constantly try to define themselves while attempting to fit into mainstream society and maintain their cultural/ethnic heritage. Therefore, experiences where mainstream Canada and the system discriminates against racialized newcomer youth, it holds a negative impact on the self-esteem of newcomer youth and forces them to choose one identity to belong to. Generally, they are forced to choose mainstream society in order to fit-in. This decision-making process can be an arduous one and research shows that perceived discrimination clearly and systematically increases acculturative stress and behavioral symptoms, and decreases self-esteem and life satisfaction (Cooper, 2008).

"During the focus group, a discussion ensued where a participant stated that he felt like 2 different people. He explained that he constantly finds himself trying to appease his family by upholding his cultural and religious beliefs and practices. However, the fear that he will be ridiculed at school makes him act like a different person when he is out of his home.

"Sometimes, I even get worried when I'm walking down the road with my pants down and making a lot of noise with my friends. Because if anyone from my family sees me, I'm for sure done!" A Rising Researcher 
(Godwin, 2017)

A question from the survey administered by the Rising Researchers shows that 72\% (32 out of 44) respondents did not feel like they could be themselves both at home and at school (Godwin, 2017). The struggle of developing an identity for any adolescent is an onerous one, and when coupled with the feeling of displacement through migration to an unfamiliar place with new and different customs, it becomes detrimental to growth and mental well-being of newcomer youth. Unfortunately, such personal difficulties of creating new social networks and relationships led to negative psychological outcomes for newcomers such as stress, anxiety, and loneliness (Chuang et al, 2010).

Additional burden is sometimes also placed on some newcomer youth who are from a family where their parents do not speak English. As some parents' level of English proficiency may be limited, parents relied on their adolescent children to be their language broker (interpreter). Unfortunately for some youth, this level of responsibility had interfered with their own personal responsibilities and placed them in difficult situations where balancing their family and school/ work life may be complicated at times. (Chuang et al, 2010).

As newcomer youth go this stage of identity development in a new country, experiencing what is acceptable and what is frowned upon in this new space, they quickly learn through social cues how to conduct themselves. Through the lens of Social Learning theory, we are able to assess the role Canadian society plays in the identity formation of newcomer youth that leads them astray. The process of making new friends (as evidenced above) is a grueling process on its own and can lead to the adoption of negative behaviours. The application of this theory signifies the 
possibility that newcomer youth's involvement in illegal activities can easily be addressed as a learned behaviour that was developed within the context of integration.

\section{Mental health:}

Very little work exists about the mental health of newcomer youth. However, in order for newcomer youth to successfully integrate, it is imperative that their mental health status is acknowledged and addressed. International and national research has shown that immigrants are at higher risk of experiencing some mental health conditions, including psychosis, schizophrenia and post-traumatic stress disorder (PTSD) (Newcomer Health in Toronto, 2011). Newcomer youth may suffer from mental health related issues that stem from an array of experiences; they may face stress over adaptation to the host society, including cross-pressure from parents' and peers' norms, values, and expectations (Mood et al, 2016). “Traumatic pre-migration experiences also have been found to have had an impact on newcomer youth and their experiences in settling and integrating into Canadian society. Many youth witnessed injuries to members of their families as a consequence of ethnic cleansing, combat and/or constant gunfire. The groups of youths most frequently associated with these types of experiences included youth from Somalia, Afghanistan, and the former Yugoslavia (Anisef, 2005). In general, and coming as they do from a completely different environment, these children are at risk of academic difficulties, low self-esteem, behavioral disorders, depression, anorexia nervosa, and somatic symptoms (Skokauskas et al, 2009).

"So many of the newcomer youth in conflict with the law that I have encountered have had some form of mental illness and many of them have not 
been diagnosed prior to their involvement in the criminal justice system. And

for some, in their countries, it is a taboo to talk about mental health, let along

accept their mental health status. So, when we work with them, we keep

having to tread very carefully around that subject with the youth and their

parents, but it does need to be discussed"

Interview participant.

Some newcomer youth who suffer from mental illnesses are unable to disclose their condition for many reasons including their inability to identify that they suffer from a mental illness but also from the feeling of not having anyone to confide in. Program participants expressed that in most of their cultures, mental illness is not discussed or acknowledged. There is a lot of stigma associated with mental illness and none of them will want to disclose information about their mental health for fear of being stigmatized. (Godwin, 2017). The stigma associated with mental health within their culture coupled with the potential inability to identify a strong support system in Canada can increase the isolation felt by a young person experiencing mental health challenges. Immigrant children are not only exposed to particular stressors that make them more vulnerable to psychological, social, and academic problems, but also have few support systems. For those who seek help for their children, barriers to professional help include not only language and culture difficulties, but also unfamiliarity with local health and social systems, and fear of the authorities. When referred by others, immigrant families are also less likely to engage with services, failing their first appointment (Skokauskas et al, 2009).

The presence of mental health challenges amongst newcomer youth and the lack of support available to reduce the impact of the challenges can be linked to their potential involvement in 
illegal activities or delinquent behaviors. Dual involvement with the mental health system and justice system is relatively frequent for young adults with mental health problems, yet the research on factors predictive of dual involvement is incomplete. Of particular concern are adolescents and young adults in the mental health and juvenile justice systems who are transitioning into adulthood. Criminal behavior peaks during late adolescence and young adulthood, roughly from 16 to 25 years of age. (Pullman, 2010). Often, the institutional rules and regulations governing supportive services such as community mental health or child welfare are restricted by age. These services may end at 18 or 19 years of age, forcing an unwelcome institutional transition prior to the developmental transition into emotional maturity. Young adults in these situations are extremely vulnerable to negative influences from their neighborhood and peers, and developmentally are less able to control their impulses or plan for the future (Pullman, 2010). "During this time, the repercussions of violating the law suddenly become much more severe, as social policy for adults who exhibit problematic behavior tends to be more punitive and reliant on the criminal justice system" (Pullman, 2010).

In this context, the functionalist theory is most applicable as it assesses the roles played by all parties involved (the state, the individual and society). The absence of support from the state for newcomer youth, coupled with the stigma from society and the individual's potential unwillingness to accept their mental health status, interrupts their integration process; thus, increasing their potential involvement in behaviors that are not consistent with those of a wellintegrated law abiding citizen. 


\section{Systemic barriers:}

Systemic barriers as defined by Canadian Race Relations is the institutionalization of discrimination through policies and practices which may appear neutral on the surface but which have an exclusionary impact on particular groups, such that various minority groups are discriminated against intentionally or unintentionally. The most common barrier newcomers experience is the barrier to information. This barrier is entrenched for newcomer youth in their immigration experience- prior to even arriving in Canada.

\section{Immigration experience:}

Restarting one's life in a new country requires access to resources, one of the most important being accurate, timely information. Information is vital to recently arrived immigrants and refugees, as it can facilitate access to housing, health care, education, and employment, and facilitate newcomers' subsequent inclusion into the social and political fabric of Canadian life (Quirke, 2011)

In describing his initial feelings during the immigration process, the 15 -year-old Colombian Quebec boy stated that he felt "like a piece of grass in a big field." (Chuang et al, 2010). Newcomer youth are not addressed during the immigration process due to the fact that they are minors and considered dependents. They go through the entire process of migration with no information offered to them about their destination country; they arrive in Canada, ill-prepared to adapt. 
Lack of information is a serious problem for many newcomers. The majority of respondents to a survey in Halton (Meneses, 1999) had little or no knowledge about the critical issues that they would have to deal with in their settlement process. Other than receiving the Ontario Health Insurance Plan (OHIP) and making an appointment with a doctor, few knew how to access other health care services (e.g.: mental health, drug and alcohol problems, and nutrition). (OxmanMartinez et al, 2012). Although lack of information affects all immigrants, the effects are far more detrimental to newcomer youth as no one ever thinks to provide information to them on account of their young age. The feeling of isolation and insignificance starts at this point. But perhaps there is hope- they may gain insightful information on their new home country once they are enrolled in school. It is important to note that the ministry of Immigration, Refugees, and Citizenship (IRCC) funds a program called the Canadian Orientation Abroad program. This program offers overseas orientation to visa-ready migrants to ensure they make informed settlement decisions (COA, 2016). While this effort is admirable and speaks to the kind of support newcomer youth wish they had, it leaves a large gap. The program caters to the applicants, thereby neglecting the children and further enforcing the discourse that ministry provided supports only cater to migrants of working age.

After all, systems such as the education system are quite neutral and accommodating. And they are, on the surface. Unfortunately, contrary to the expectations of newcomer youth, the school presents a great barrier in more ways than they imagined and these barriers will heavily impact them. Certain institutional barriers that exist pose a problem towards the successful integration of newcomer youth, especially as it relates to education and social inclusion and these barriers have the potential to further alienate newcomer youth. It is thus imperative that settlement structures and processes are designed with consideration and in-depth understanding of the traditions, 
learning aptitudes, family structures and moral values of immigrant and refugee youth to successfully meet their educational needs (Anisef, 2005).

\section{School system:}

As youth spent a significant portion of their time in school and school systems differ across the world, it was expected that newcomers would experience some level of school adjustment problems (Chuang et al, 2010). It is in this space that newcomer youth spend most of their time; this is where they learn what it means to be Canadian, this is where they should feel safest. It is also where they should feel most supported.

One of the most critical factors in a successful transition into Canadian society is education (Rossiter et al, 2009). The education system is an ideal setting for the delivery of resources as newcomer youth often enter into the education system shortly after arriving to their host country, and thus it is able to provide newcomer youth a sense of direction (Deckers et al, 2012).

Ideally, newcomer youth will be warmly received by their new school and a plan to help them succeed beyond academics will be developed with the youth and their parents. They will be supported by their teachers and guidance counsellors on things like class selections, joining social groups/clubs, exploring interests that may be similar to what they did in their home country, information and access to resources, etc. Teachers, guidance counsellors will provide a safe space for newcomer youth, similar to what some students in Rossiter \& Rossiter (2009)'s study said about their coping supports. "The development of positive relationships with caring adults in the school setting, such as ESL or mainstream teachers, counsellors, and School Resource Officers, was also considered to be a protective factor. In some schools, members of 
ethno-cultural communities offer approved courses designed to help students develop identity and intercultural competence. Here, immigrant youth can begin to make decisions about various aspects of their home and adopted cultures" (Rossiter \& Rossiter, 2009).

Unfortunately, this is simply an ideal case. It is not the reality that most newcomer youth endure in their new schools. The same study by Rossiter and Rossiter (2009) highlights the school system -especially authoritative figures within the schools- as being risk factors for newcomer youth's potential delinquency. "Participants in the study criticised low teacher-student ratios and the lack of resources and appropriate programming for ESL youth. They noted that many staff have low expectations of newcomers and little or no understanding of the educational, cultural, and family backgrounds that might help them to understand these students (Rossiter \& Rossiter, 2009).

Naturally, newcomer youth look to teachers, guidance counsellors, principals and other authoritative figures to assess where they fit in and how to behave. They also rely on information from these figures to make decisions, especially when they come from a household where there may be limited understanding of the Canadian education system. Numerous elements such as teacher biases, economic inequality, and institutional or systemic discrimination act as barriers for immigrant youth in the attainment of equal educational opportunities (Anisef et al, 2000). Rising Researchers participants unanimously responded in one of the sessions that they did not feel supported by their teachers or guidance counsellor (Godwin, 2017).

[They] "feel that there is a lack of support in school and if you need extra help you are ignored and out casted" (Rising Researcher) 
Newcomer youth repeatedly reported being misguided by their teachers and guidance counsellors. With limited access to information and limited knowledge on the school system, newcomer youth and their families are usually under the impression that the school's authoritative figures know best and will always act in the best interest of the student(s). Results from a study conducted by Oxman-Martinez et al (2012) indicated that among all immigrant youth's and mothers' groups, concern was expressed around the placement of youth into academically appropriate grades and levels of course work at the secondary level (Basic, General or Advanced). For most immigrant groups, there was general frustration and disillusionment with schools placing students into levels lower than they felt they were capable of. Language difficulties, racism, and discrimination against immigrants were identified by youth and parents as often being linked to placements into lower level classes or grades. Only very few students and parents noted guidance counsellors as helpful. In fact, many youth noted guidance counsellors as being implicated in the many problems these youths faced. The current findings suggest that other immigrant, non-English speaking students (as well as African Canadians) are also experiencing systemic and structural streaming into low levels of study and manifesting poor academic achievement (Oxman-Martinez et al, 2012).

Participants in the PAR project [also] expressed having a hard time saying no to their guidance counsellors when they are asked to take certain classes as they believe the counsellors know best (Godwin, 2017). Under the illusion that the guidance counsellors are acting in their best interests, newcomer youth make irreversible decisions that will hinder their academic plans/goals for years to come. 
In Chuang's 2010 study on the settlement pathways of newcomer youth, one of the participants expressed a common experience among many newcomer youth. The participant expressed difficulty with understanding their guidance counsellor and resorted to answering yes for every question they were asked. This resulted in being enrolled in applied courses despite their desire to attend university after high school.

Two years ago, I kept talking to my guidance [counsellor] and I don't understand. She kept telling me, asking me questions, and I kept saying 'Yes, yes, yes'. After one year, I wanted to go to university but I took all my courses applied. I told her, 'Why did you give me applied?' She told me that 'You told me that. I asked you.' So I had to change all over.

(Chuang et al, 2010)

This was a common experience for most of the Rising Researcher program participants. New immigrant youth find themselves being convinced that being in the less academically challenging classes will be better for them. The literature around newcomer youth confirms that they are usually placed in ESL classes even when they speak and write English fluently, simply because they may have a heavy accent or come from a country where the primary language is not English (Godwin, 2017).

...There were significant numbers of individuals who spoke English as a (or one of) native dialect. However, their general language problems were based on how they spoke English, their accent, resulting in similar challenges in communicating with others. As various English speaking countries have their own unique intonations and stress marks on words, some 
youth complained that peers and teachers were not able to understand their accent. As a 16-year old Kenyan BC girl expressed,

My problem wasn't really language but my accent...I never knew I had an accent until I came here and the way I pronounce words is closer to... a mixture of Jamaican and British accent...Apparently, people couldn't understand what I was saying. (Chuang et al, 2010).

The lack of support from teachers and guidance counsellors only further intensifies the impact of the other challenges newcomer youth face in school settings. Many youth spoke to the challenges they faced in dealing with the grading procedures and curriculum as well as how schools function (i.e., rules and regulation) (38 youth, 34\%). Most immigrants had previous school experience and expertise from their homeland but unfortunately, many aspects of their previous knowledge were neither transferrable nor relevant to the Canadian system. (Chuang et al, 2010).

Most research documents on newcomer youth's integration experience highlights this as a common theme (Chuang et al, 2010; Rossiter et Rossiter, 2009). Similar to the experiences their adult counterparts face in having their work and education accredited, newcomer youth participants in the PAR research report that they are often de-credited or under-credited for their academic achievements in their home country. One of the Rising Researchers (at the brinks of tears) explained the difficulty endured in their first semester at a Canadian high school. They were informed by their guidance counsellor, who had difficulty understanding their accent, that the student would need to be placed in ESL and applied classes so as to ease them into the Canadian school system. While this guidance counsellor may not have been acting maliciously, the experience of the student highlights a problematic issue. This Rising Researcher was a high 
achiever in their home country and spoke English fluently while having a specific passion for poetry. They unfortunately lost a semester trying to convince the school that they were capable of handling academic courses and planned to attend university. It was an enduring process for the student whose family could not provide additional support and advocacy due to work obligations; the result was the student going through this alone (Godwin, 2017).

"I've had to go into the schools myself and address some of these issues with these teachers. One of my youth was enrolled in another school after he was expelled from his original school. At the new school, they claimed he has no Canadian credit and would need to start from scratch. His previous school had placed him in grade 10 based on his test scores, but this new school tried to convince him that it would be for his own good if he started over. Sometimes I wonder what would have happened if he didn't have me to advocate for him" Interview Participant.

In response to a question about the capacity of the education system to integrate newcomer youth and their performance so far, both interview participants expressed that the school system is inadequately equipped to provide the necessary supports to newcomer youth. "And to be honest, a lot of it is based on the high student to low teacher ratio. There is a lot on their plate and it takes a lot of time and attention to give newcomer youth the support they deserve. My youth tell me all the time that their teachers barely talk to them, unless they are late to hand in an assignment. One of them was incarcerated for a few months and his teacher did not even notice he was gone until a few weeks later" Interview Participant. 
As outlined above, the school system holds great potential to successfully integrate newcomer youth and provide a safe learning environment for them to thrive. However, it appears to be lacking in this area as has been reported by students and their external adult allies. These practices by teachers and guidance counsellor forces you to wonder if it is discrimination practiced by the people within the school or if these are policies entrenched within the school system that are designed to fail members of certain marginalized groups. The probability is higher with the latter than it is with the former.

\section{Discrimination:}

Discrimination is a salient stressor that immigrant families encounter after migration. Using a critical race theory lens, we can assess the institutional barriers present in the Canadian education system for newcomer youth and how they further propel racialized newcomer youth into gang and criminal activities. As per Crichlow (2015), Critical Race Theory is a conceptual tool designed to challenge the colorblind notion of law; the neutrality of law; subtle forms of racism; racial discrimination in law, as well as suggest how law can be used as a tool to challenge racism. Through this lens, it is important to emphasize the intersectionality of other factors that play a role in the marginalization of the newcomer youth populations (race, religion, socioeconomic status, etc.).

"Intersectionality holds that the classical conceptualizations of oppression within society, such as racism, sexism, homophobia, and religion-based bigotry, do not act independently of one another; instead, these forms of oppression interrelate, are tied to each other or are connected to each other creating a system or faces of oppression that reflects the "intersection" of multiple 
forms of discrimination" (Crichlow, 2015). Unfortunately, Canada does not release to the public crime statistics related to race and ethnicity (Rossiter et al, 2009)

\section{Discrimination by authoritative figures}

At school, discrimination expressed by teachers and other students is a significant source of social exclusion. Research on academic adjustment of immigrant students (Suarez-Orozco et al., 2009) suggested that students belonging to ethnic minority groups experienced negative ethnic stereotypes and diminished academic expectations by teachers and other staff because of their ethnic background. (Oxman-Martinez). When discussing how newcomer youth respond to discrimination, an interview participant had this to say:

"For them it's crazy. It's so new to them that it takes them a while to realize that they are being treated differently because of their religion, their race, their accent, etc. And in a country like Canada, it is almost easier to assume that the experience is yours alone because when you look around and see that there are others who look like you, it's hard to believe that it is a race thing or a religious thing” Interview Participant.

Within the school setting, several youth across the nation were distressed by the level of discrimination and racism expressed by their teachers, school administrators, and the school system, more generally. Thirteen youth spoke about this issue (11\%) which was difficult to openly discuss such negative situations as most of the youth consistently emphasized throughout the focus groups the importance of students respecting their teachers. One 18-year-old Nigerian 
Ontario girl recalled,

I went to my science class... and my teacher was like, 'Oh, tell me the story about Africa' and whatever. So, I was telling her about the story and everything and suddenly she was like, 'Oh, do African people sleep in trees?' ... [crying] It makes me so sad because you don't just judge people just because you're black and whatever she's used to...Like and I told her that we have houses. Most people ask me the questions like, 'Where do you live?' instead of just, 'Do African people sleep in trees?'... Why would you even say that? You are my teacher.

(Chuang et al, 2010)

Another form of negative behaviour focused on discriminatory and racist remarks and behaviours but unlike anti-social behaviours, these actions was perpetrated by not only their similar-aged cohort but by teachers, the school administration, and the community at large (32 youth, 29\%) (Chuang et al, 2010). "Education is considered to be a liberating force towards the equalization of opportunities in an ethnically stratified society; however, many studies have found that equal educational opportunities in Canada are limited for some ethnic groups" (Anisef et al, 2000). Race based discrimination within the school system was also identified as a barrier for the Rising Research project participants (Godwin, 2017).

Others may often wonder why newcomer youth won't speak up for themselves in the face of such blatant discrimination. For most newcomer youth, their home country/ culture frowns against defying authoritative figures, especially teachers. However, those who are brave enough to stand up for themselves are still met with resistance and often ridiculed. "Even when youth attempted to explain their particular background, some teachers became rigid in their attitudes 
and beliefs about immigrants and typologized them into one stereotypic group. As one frustrated youth (17-year-old Ontario girl from India) expressed,

When I came to Canada, I gave my schedule to my science teacher and he was like, 'How come you don't have ESL?' I told him that I studied English in my country and he was like, "No, no you can't study English here. Go back to ESL, the first level, and then come back to academic English. '...He just kept telling me for a week to go and I went to a counselor because I didn't know what ESL was at that time, and the counselor was like, 'Well, you [took] an exam and you got almost perfect so I don't think you should go." (Chuang et al, 2010)

Another study by Shakya et al, 2010, highlighted discrimination and racism newcomer youth encountered at schools from authoritative figures. Youth respondents recounted with sadness the direct experiences of race-based discrimination that they have faced or witnessed, often from teachers and people who are supposed to assist youth. Youth talked about being shocked, 'hurt' and 'getting really mad' due to these experiences of race-based discrimination (Shakya et al, 2010). In his study of Canadian high school students, Anisef (1994) found that some visible minority children not only performed poorly in class but suffered behavioral problems as well and pointed to teachers' discriminatory attitudes and behaviors as generating factors (OxmanMartinez et al, 2012).

In the PAR project, one participant had the authenticity of their assignment questioned with the teacher stating that "it was too academic" for the student. The student had an accent and did not speak the way they wrote so the teacher refused to believe that it was original work. As a result, 
the teacher gave the student a zero because they thought it was plagiarized although there was a lack of proof. This student felt insulted and ultimately discouraged to make an effort towards school. This student dropped out of school less than 6 months later (Godwin, 2017).

Similarly, one interview respondent recalled a story she was told by a former client. The youth expressed that within his first few months in Canada, he was also suspended twice over a teacher's accusation that he was cheating on a test.

"This kid was just very good at the subject and the education he had received in his home country was ahead of what he was being taught here. And the worse part was that the teacher had no proof that he was cheating, his rationale was that the kid didn't talk in class and when he's called on to answer questions out loud, he doesn't say anything. So, to that teacher, it didn't make any sense that this foreign student would be able to get all of the questions right when he barely spoke in class. The truth was the kid really was shy and was getting bullied by other kids in the class. So, he didn't want to show off and answer questions out loud-he also had a heavy accent. After the second time he got in trouble, he started intentionally getting answers wrong and went from an A student to barely making Cs. - Interview Participant

“This environment has proven to be a negative one for newcomer students. It has led to poor attendance, fostered feelings of hostility towards school and produced an increase in delinquent behavior." (Anisef et al, 2000). At such a young age and vulnerable stage, newcomer youth can 
barely grasp that it is a systems issues. Instead, they internalize these encounters and fall victim to the stereotypes.

\section{Discrimination by peers}

Building relationships. As youth enter a new country, they need to re-establish a social network of friendships and relationships. Especially in school settings where youth spend a significant amount of their time together, peer relations becomes an important part of their lives. (Chuang et al, 2010).

Unfortunately, in the context of incidences of anti-social behaviours and deviancy, most offences were described as primarily being perpetrated by their peers. Of the responses (32 youth; 29\%), youth mentioned peer pressure, various forms of physical and psychological (i.e., social exclusion, teasing) aggression, as well as bullying tactics (a more serious form of aggression where individuals were targeted rather than being randomly victimized). (Chuang et al, 2010).

In addition to facing discrimination from authoritative figures within the school, newcomer youth also report being bullied on ground of their ethnic difference by their peers. The Rossiter and Rossiter (2009) study considers bullying at the school a significant problem that prevents the integration of immigrant/refugee children. The more affected are refugee children and children from racially marginalized groups.

A researcher in the Godwin (2017) study stated: 
"I have been here for six years and when I first started school it was tough. The school I went to was not diverse. I wanted to be part of the class so I started acting like the other students, being wild and causing problems because I wanted to fit in and be cool. I really wanted friends and it was hard. I got bullied a lot because of my accent and being different. One day another kid told me to get out of my chair and pulled my bag. I had enough and stood up for myself and in the end, I got suspended. Before, at that time, I just accepted because I didn't know what to do, who to tell and whether anyone would believe me and I felt like I had no support. At one point, I did not want to go back to school anymore"

Also, some youth interpreted the aggressors' motives as being specifically targeted to newcomers rather than to youth in general. As one 18-year-old Chinese Ontario girl stated, "You have no friends... There are a lot of people who are trying to bully you cuz you don't speak English and you don't have any friends. You're lonely."(Chuang et al, 2010).

Social exclusion as a multidimensional process of progressive social rupture, detaching groups and individuals from social relations and institutions and preventing them from full participation in the normatively prescribed activities of the society in which they live. (Oxman-Martinez, et al, (2012). These experiences affect newcomer youth social inclusion when they begin their lives and continue on through the life-course within the host country. Fostering environments of social inclusion may provide experiences for successful integration into Canada for youth populations (Thomas, 2012). 
In response to the question of the types of crimes most committed by the newcomer youth they support, one of the interview participants stated that physical violence is one of the most common offences.

"They get in a lot of fights and most of the time they are just standing up for themselves. These other kids bully them to the point where they can't take it anymore. And since the school is already biased against them, it is easier to call the cops on them instead of handling the matter from the root cause"-

Interview Participant.

Physical violence in response to bullying in schools with zero tolerance policies, puts them at risk of suspension or expulsion. In a study by Choi and Lim (2014), newcomer Asian youth lost faith and trust in the education system because of the outcomes of their racial encounters that lead to their further victimization by the school and school authorities. One participant mentioned getting into a fight because of a racially charged bullying incident and was placed on detention by teachers who pretended to have difficulties understanding him due to language barriers. This provides a classic example of the lack of support available for racialized newcomer youth in institutions of education. It also sheds light on the fact that the lack of protection available within the school system leads racialized newcomer youth to believe that they must physically defend themselves from bullies. (Godwin, 2017).

Quite often, when newcomer youth engage in physical altercations at school, they are turned over to the police and charged. Unfortunately, discrimination based on race and ethnicity is not limited to experiences within the school. There is a great tendency within the police system to criminalize the activities of immigrant youth, especially racialized newcomer youth. When 
immigrant youth have conflict with the law, they experience a wide range of issues in their contact with police and youth justice court procedures. These include distrust and fear of authority figures, limited knowledge about the Canadian justice system, lack of understanding of their constitutional rights, problems understanding and providing accurate information during investigation and court proceedings due to limited English, and cultural misinterpretation in communication (Schleifer et al, 2005).

For some newcomer youth, their first encounter with the police is not when they have committed a crime, but when they are walking home. Socially, racialized people tend to gravitate towards each other. When newcomer youth find themselves on the outskirts of the norm, they gravitate towards other similarly situated youth who are on the outskirts as well. Unfortunately, these racialized groups are also highly policed, especially in low income communities (Godwin, 2017). Newcomer youth in the PAR project expressed their frustration at being stopped while walking home for now reason. It was a new and traumatizing experience for him and changed the way he viewed police.

"The first time a cop stopped me on the street, I almost cried man. I was so scared. I thought for sure they were gonna send me to jail. But he was just asking me questions about where I was going and my name and stuff like that. I didn't understand it at all. And when I asked him why he was asking me so many questions, he got mad and asked me if I wanted him to arrest me. Man, I was so scared. But I didn't tell anyone. Now I just hate cops and I don't want them to talk to me” -A Rising Researcher. (Godwin, 2017). 
Certain immigrant/ethnic minority groups may be overrepresented in crime statistics because, compared to the native born, they are more likely to come under intense police surveillance (racial profiling), more likely to be arrested by the police, and more likely to be convicted and given tough sentences by the criminal courts (Janhevich, et al, 2008). In one of the sessions where we discussed experiences with police, $100 \%$ of the Rising Researchers responded that they have been stopped by the police and $60 \%$ expressed that it happened more than once (Godwin, 2017).

Both the functionalist theory and the differential association theories are reflected in the way the school system interacts with newcomer youth. Through barriers entrenched within the system that are upheld by teachers and guidance counsellors, newcomer youth encounter several roadblocks to integration directly from those who are trusted with the well-being and successful integration of these youth. When newcomer youth find that they have been failed by the system and the authoritative figures they believed should be trusted, the attempt to find solace within another space. This failure by the system can in-turn be said to have the strong potential to push newcomer youth out of mainstream society and further marginalize them. In the context of differential association theory, when newcomer youth are pushed to the outskirts, they are exposed to situations and individuals who engage in violations of the law. Thus, newcomer youth's involvement in the criminal justice system is inevitable when society and social structures fail to play their part in the integration process. 


\section{Newcomer youth- delinquency and illegal activities:}

In 1994, following a highly-publicized homicide involving a white female victim and a black male assailant, the Canadian media began to draw a direct connection between immigration and violent crime (Wortley, 2009). Cross-national research has documented that the level of immigrant involvement in crime may be related to how well they are received by host nations (Wortley, 2009).

Much of the policy discussion concerning immigration, ethnicity, and crime has focused on the issues of gangs, organized crime, and terrorism. Even a casual review of the historical record reveals that this concern over immigration and gang activity is not new. During the late nineteenth century, for example, the North American focus was on crimes committed by Jewish, German, Polish, and Irish immigrant gangs. Today, the focus in much of Europe and North America has turned to gangs from Africa, the Caribbean, Asia, Russia, and the Middle East (Wortley, 2009). Unfortunately, the available research on immigration, ethnicity, and crime is rather limited (Wortley, 2009) in Canada. To provide additional context on the relation between integration or settlement and criminal activities amongst newcomer youth, I will delve into research outside of Canada.

While most researchers argue against the common public discourse that immigrants commit more crimes than their non-immigrant counterpart (Chen et al, 2013; Rossiter et Rossiter 2009; Wortley 2009; Salmi et al, 2015), there still remains a correlation between immigrants and criminal activities. A large body of research showed that as a group foreign-born youth were less likely than their native-born peers to engage in risk behaviors but high levels of youth crime 
among certain immigrant groups in different locations and times were also documented. For example, immigrant youth from Southeast Asia living in California were found to be more likely than Whites and members of more established Asian groups to engage in criminal activity. The purpose of this research is not to conclude that newcomer youth commit more crimes than their Canadian born counterpart, rather it is to identify the different barriers that may push newcomer youth into criminal activities. To better understand the correlation, researchers have employed a multitude of theoretical traditions, including the strain theory and cultural conflict (Salmi et al, 2015). "The cultural conflict explanation rests on the idea of different norms between the country of origin and the new host nation. Immigrants might maintain behaviour or cultural practices, such as corporal punishment or the use of certain drugs, that are in conflict with the laws and norms of their new home country" (Salmi et al, 2015; Wortley, 2009). This explanation aligns well with some of the aforementioned barriers newcomer youth encounter during integration and settlement.

The involvement in gangs and criminal activities by newcomer youth is perpetuated by the circumstances that surround their migration and integration into Canada. "It is acculturation into American society that causes immigrants, especially second and above generations, to become more like native-born peers in all ways - including involvement in crime and delinquency" (Chen et al, 2013). Youth at the beginning of their settlement trajectory are least likely to become gang-involved, but this risk increases with number of years in Canada (Sersli et al, 2010). The attraction to gang activities for newcomer youth can easily be aligned with the feeling of loneliness and isolation that they experience. Newcomer youth may face isolation as they are without the social supports they had in their homeland and are left without the ties, such as family and friendships that assist with social inclusion. So, when newcomer youth who have 
been isolated, eventually make friends who welcome them into their circle, it is difficult for them to see these friends as anything else. For newcomer youth, especially racialized newcomer youth, the aforementioned barriers work together to produce low self-esteem, poor motivation to learn and a higher desire to find like-minded people- those who also do not belong to the mainstream society (Godwin, 2017). Migration researchers also argue that young generations of immigrants are different from adult immigrants in that they are more likely to fall into neurotic marginality (anxiously trying to meet the demands of both cultures), become "escapists" (alienated from both their original and the host societies), choose downward assimilation (over-emphasizing their culture of origin), or go toward over-acculturation (over-identifying with the mainstream culture) (Chen et al, 2013). Unfortunately, this may mean that newcomer youth may find themselves entrenched in gangs and criminal activities and sometimes it may be too late for them. In response to the question on what the respondents thought got newcomer youth into gang activities, one mentioned acceptance.

"These youth are looking for belonging. They are lonely and looking for friends; they need love. And you have these gangs that are already here and they know how to prey on vulnerable youth like newcomers. They find them when they are alone, they make friends with them and the youth thinks all of his worries are gone now. He has friends now. They take care of him, they show him love and show him Canada. They teach him how to be Canadian. And then before he even realizes it, he's now in a gang"-Interview Participant.

Many immigrants, as described by Wortley (2003), do not understand Canada's justice system and end up unintentionally in conflict with the law (Rossiter \& Rossiter, 2009). Many who are gang involved, find themselves there unintentionally. Two of the Rising Researcher participants 
shared their story of being labelled as part of a gang without realizing they were in a gang. They were always out of the class as they did not feel like they belonged in the classes and were not motivated to try harder. When they skip classes, they usually see the same group of youth outside the school and they started spending time with those guys. One day they were walking in the hallway at their school and one of their friends pulled the fire alarm. They were called to the office and suspended, citing gang activities (Godwin, 2017).

Some youth are lured into gangs through certain activities that are new to them. Youth talked about how they were offered cigarettes and alcohol which were new personal experiences for them. Specifically, a 16-year-old El Salvadorian BC boy said,

I have been with people who tell me, 'Here a cigarette', or 'Here drink this,' right? So I have to be like, 'No, thank you.'... Because like if I go and I start to do this stuff I would be gone, right?...In my country - never seen that before. (Chuang et al, 2010).

These anecdotes provide a different angle to the discourse around newcomer youth and gang involvement. Popular discourse holds that newcomer youth come to Canada to get in gangs and commit crimes. We see rather that newcomer youth are lured into gangs after the system fails them.

In addition to violent offences, one of the interview participants cited finance related crimes as the second highest crimes committed by the newcomer youth in they support.

"I think violence is definitely the top one. They have so much anger in them and I can't blame them for being angry. The system really fails them. But another one is robbery and theft. Honestly, finance related crimes are up there for them. A 
lot of them, their families are struggling to make ends meet. And when the kids start making friends, they want to dress like their new friends, but their parents can't afford these clothes and shoes. So they steal. Or some of them will threaten another kid to give them their shoes and clothes. The ones who are in gangs, theft and robbery is the most common charges for them.

-Interview Participant.

Furthermore, the process these young people go through as they navigate the legal system with parents who have very limited understanding of the judicial system usually means that they end up re-offending shortly after, as the process did not provide any more information for them. And thus, ensues the cycle of offending for newcomer youth.

\section{Limitations of the study}

With the limitation of time imposed on a graduate level research paper, as well as the number of participants in the interview, the types of research one could conduct is understandably small. The methods of research conducted is also limited by the lengthy and laborious process of obtaining ethics approval for research involving human subjects. Ideally, this research would have included surveys completed by newcomer youth, some focus groups and interviews, as well as interviews of a larger number of service providers and parents of newcomer youth who have been in conflict with the law and/or gang involved. Additionally, access to demographic data on youth crimes, including migration/citizenship status would have strengthened this research. 
Separate interviews would have been conducted for authoritative figures within the school system to get a better understanding on the limitations they face in providing adequate services to newcomer youth. Additionally, they would also be able to provide insight on factors that they believe propel newcomer youth into gangs and/or criminal activities.

Police officers would have also provided significant insight on their experiences with newcomer youth and families, as well as recommendations on how to better support their use of alternative justice methods.

Interviews or focus groups with parents of newcomer youth who have been in conflict with the law and/or gang involved would have enriched the information, especially around the differences they notice in youth's behaviours as they integrate into Canada. Additionally, parents will be able to shed light on their limitation to provide support for their children through the resettlement.

Finally, the scope would have also been widened to the entire Greater Toronto Area to ensure a well-rounded data is gathered.

\section{Findings}

A disservice is done to newcomer youth from the moment they are granted residency in Canada. As the research around newcomer youth becomes increasingly available, it gradually becomes clear that newcomer youth's involvement in illegal activities is not something they arrived in the 
country with the intention of committing, rather it is an outcome of the system that our migration and integration process funnels them through.

As dependents and minors during the migration process, they are not the focus of the immigration body- those who are able to contribute to the Canadian economy immediately are the focus. I must point out the irony in this practice as newcomer youth are most likely going to live in Canada longer than their parents and will therefore contribute more to the Canadian economy, but the short-sightedness of the immigration government manifests itself. Little to no information is provided to the newcomer youth and they migrate to a new country they most likely know nothing about. The popular concept of youths' resilience is relied upon and newcomer youth are expected to integrate seamlessly, especially when they start school.

The school system is said to be the place where newcomer youth will thrive and continue on with life with little signs of disruption. Sadly, this is but a fairy tale for many newcomer youth. Research has shown that the expectations of integration through the school system and the reality paint two different pictures. In reality, the newcomer youth are not warmly welcomed by their teachers and peers. They are not consulted on decisions that affect them, they do not seamlessly continue with their education, they do not easily fit in, they do not instantly make friends. At least not all of them do. Rather, they struggle. They are faced with teachers who are unwelcoming and hold strong biases against them based on their differences. Their efforts are condemned by the school and their works are questioned and labelled illegitimate. Newcomer youth are criminalized by authoritative figures before they even commit a crime. 
They are ostracized and bullied by their peers. Their confusion and feeling of isolation worsens as they are pushed out in all different ways. Faced with the onerous task of providing for a family in a country where their credentials are not recognized or they have no credentials to speak of, parents are unavailable to provide support to the youth. In a new country, with no friends and no support from teachers or home, and trying to develop their identity and understand how they fit into this space can be tasking for anyone, let alone an adolescent youth.

In this state, the first hand that stretches out to them with kindness and compassion is eagerly welcomed. Sadly, the outstretched hand does not always mean well- it is often bad company looking for a new recruit. Nonetheless, a once lost and lonely newcomer now has friends and has gained a sense of belonging. To avoid returning to the dark space of loneliness and rejection, they will do whatever it takes to keep their new-found camaraderie. Even if that means stealing a few things, and partaking in activities they normally would frown upon. And thus, is the path through which newcomer youth are ignored by the immigration government, fall through the cracks of the education system and end up in the criminal justice system.

\section{Conclusion}

Through the assessment of research literature on newcomer youth's integration experience, focusing on Godwin's (2017) Participatory Action Research project involving newcomer youth in conflict with the law, Chuang et al's (2010) study on settlement pathways of newcomer youth and my interviews with two service providers who support newcomer youth in conflict with the law, I have surmised that many pitfalls caused largely by external/systemic factors create gaps in 
the integration process for newcomer youth and increases their potential participation in illegal activities.

Through systemically embedded discrimination within the school system, newcomer youth are often pushed out from the same spaces that are meant to welcome them and support their integration. Of course, these systemic barriers do not independently push newcomer youth into gangs and criminal activities. A combination of these systemic factors and individual factors play a role in these outcomes. The settlement and integration process is increasingly challenging for youth when coupled with the trials and tribulations of the adolescent stage of life. However, as the stage of adolescence and the struggles that come with it are unavoidable, recommendations on supporting the successful integration of newcomer youth in order to reduce the risk of further marginalization leading to illegal activities, will be focused on the systemic factors that heavily contribute to their engagement in these activities.

\section{Recommendations}

In the context of the "children/youth are our future", it is saddening to see that the Canadian government pays such little attention to the youth within their main source of population growth. Although these young people are generally unable to participate in the economy today, it is imperative that we provide a system that supports their positive development, growth and integration so that they can continue to thrive and eventually contribute to the economy. My recommendations are aimed at the institutional policies and practices in immigration, education and law enforcement. 


\section{Immigration:}

The experience of immigration plays a big role in how newcomer youth receive their new home country. The absence of information directed to newcomer youth to support their integration leaves them to discover on their own. This increases the risk of participating in activities that are illegal in Canada. Some activities may be legal and commonly engaged in by youth in their previous country that may be illegal or frowned upon in Canada. An example of this is the ability of a minor to purchase and smoke cigarettes in some countries, but is against the law in Canada. Similarly, some activities that are frowned upon in other counties may be accepted and even encouraged in Canada, like arguing with an authoritative figure (teachers, guidance counsellor, etc), or going against what they advise. Similar to the pre-migration integration support provided to economic migrants and/or migrants of working age, a form of pre-migration integration support should be provided directly to the non-working age dependants.

A document specifically for newcomer youth should be provided to every family that is migrating to Canada with an adolescent. The document should include information on how to enroll in school and an explanation on how academic credits work in Canada and requirements necessary for post-secondary education and where to find more information; how to find certain resources like community hubs, libraries and organizations for certain needs; words of encouragement, stories and anecdotes of success and challenges other newcomer youth have endured in their integration phase. Additionally, the document should include contact information of the nearest settlement service provider to their future address, in the event that the youth needs someone to talk to. 


\section{Education}

As schools are considered the integration zone for newcomer youth, it is imperative that they actively uphold the practices to ensure the successful integration of newcomer youth.

Recommendations for the education system is 2 folds. First recommendation is to address the policies that directly or indirectly creates an unsafe environment or detrimental outcome for newcomer youth, especially racialized newcomer youth. Policies like zero violence tolerance are in concept great; however, in practice, they fail to assess underlying factors that lead to the violent actions. For newcomer youth, it is recommended that when they are involved in physical altercations -especially for the first time-, that they be given the opportunity to receive support in addressing the underlying factors and ensure that they are aware of and fully understand what zero violence tolerance means. Often, strict policies exist within the schools that newcomer youth are unaware of or do not fully understand what they mean.

Second recommendation is to address the practices, especially those carried out by authoritative figures, that create an unsafe environment or detrimental outcome for newcomer youth, especially racialized newcomer youth. A plan should be set in place for each school that is welcoming a newcomer youth and the plan should assign a staff specifically to that youth for a minimum of 1 year. This staff should be different from the guidance counsellor and should be very familiar with the diverse issues that newcomer youth face when they migrate to Canada. To minimize costs, some neighboring schools can share the same staff, as long as a reasonable student to staff ratio is maintained. This will reduce the misdirection of newcomer youth by teachers and guidance counsellors who are overwhelmed and possess biases towards newcomer youth. Additionally, the dedicated presence of an understanding adult ally will provide an 
opportunity for newcomer youth to ask questions without fear of judgement as they navigate their identity and settle in Canada. They will also have access to a safe space where they can discuss their experiences with peer pressure, bullying and discrimination and develop coping mechanisms to face these difficulties.

\section{Law Enforcement}

Although racial profiling is not a policy within law enforcement, it remains a practice that is upheld by many police officers, especially in immigrant populated communities. In theory, the practice is frowned upon by the police force; however, in practice, there are no repercussions for police officers who continue to practice it. Repercussions should be enforced to reduce the practice of racial profiling and carding.

In accordance with the recommendations of the Youth Criminal Justice Act, restorative practices are preferred for young offenders, especially first time offenders. Many newcomer youth are charged, often with multiple offences, in cases that could have benefitted strongly from restorative justice practices. For newcomer youth, this practice will not only give them an opportunity to express themselves and disclose information about factors that played a role in their actions, it will also offer them a second chance at being law-abiding citizens with full understanding of the law and the repercussions for breaking them. As previously stated, many newcomer youth are unfamiliar with the laws in Canada and some are not made aware that an action is illegal until they have already committed the offence and changed. 
Once newcomer youth have been charged, the process of navigating the criminal justice system is an arduous one to them and their parents/guardians. With no information on how the justice system works, newcomer families blindly try to make their way through it while often making mistakes that can be irreversible. Some newcomer youth re-offend while trying to navigate the justice system by missing a court date or two and creating the need for a warrant for their arrest, again. Other violate their probation terms because they did not fully understand them.

The navigation of the criminal justice/court systems can generally be avoided if the arresting officer had followed recommendations from the YCJA. However, for youth who must go to court, I strongly recommend that the courts immediately connect them with a settlement providing agency that is familiar with the criminal justice system, so that they can provide ongoing support for the youth and their parent/guardian.

Finally, a general recommendation for all service providers who encounter newcomer youth is to treat them as an individual and allow them to express to you who they really are, free of judgement or biases. 


\section{Appendix}

Interview Questions:

1. How long have you worked with newcomer youth?

2. Do all the youth you work with identify as newcomers?

a. If no, what percentage of your case load would you say are newcomers?

3. Do you think they integrate easily?

4. What barriers to integration do they face?

5. What are some of the individual barriers you would say the youth you work with face while integrating?

6. How do you think they fair when making new friends?

7. What are some systemic barriers you would say the youth you work with face while integrating?

8. Do you think the education system is adequately supporting the diverse integration needs of newcomer youth?

9. How do you think the school system can better support newcomer youth?

10. How would you saw the newcomer youth you've worked with have processed discrimination?

11. What do you think is lacking in the immigration process for newcomer youth?

12. Have you worked with newcomer youth who have been in conflict with the law?

13. What would you say led them to commit crimes?

14. What are the most common offences by newcomer youth in your experience?

15. Do you work with newcomer youth who are/have been gang involved?

16. What would you say led them to gang activities?

17. What supports do you think is needed to prevent their involvement in gangs or criminal justice system? 


\section{References}

AMSSA.(2016). Newcomer Youth Challenges and Strengths- A Migration Matters Factsheet.

Issue 35. Retrieved from http://www.amssa.org/wp

content/uploads/2016/12/InfoSheet35_Youth.pdf

Anisef, P., \& Kilbride, K. M. (2003). Managing two worlds: The experiences and concerns of immigrant youth in Ontario Canadian Scholar's Press.

Anisef, P., \& Kilbride, K.M. (2001). To Build on Hope: Overcoming the Challenges Facing Newcomer at risk in Ontario. Retrieved from:

http://atwork.settlement.org/downloads/Build_On_Hope_Final_Report.pdf

Anisef, P., Kilbride, K., M. (2004). The Needs of Newcomer Youth and Emerging "Best

Practices" to Meet Those Needs - Final Report [Centre of Excellence for Research on

Immigration and Settlement website]. Toronto: Author. Retrieved on, October 14, 2010, from

http://ceris.metropolis.net/frameset_e.html

Ashton, W., Pettigrew, R. N., \& Galatsanou, E. (2016). Assessment of settlement services systems in western and northern Canada: Perceptions of settlement provider organizations. Canadian Ethnic Studies, 48(3), 69-89. Retrieved from http://ezproxy.lib.ryerson.ca/login?url=http://search.proquest.com/docview/1880692373?account id $=13631$ 
Barnia, M., Hastings., \& Janhevick, D. Rethinking newcomer and minority and offending and victimization: Beyond hate crimes. Retrieved from http://canada.metropolis.net/pdfs/janhevich_rethinking_minority_crime_e.pdf

Berns-McGown, R. (2013). "I am Canadian": Challenging stereotypes about young Somali Canadians. IRPP Study, (38), 0_1.

Bertrand, L.,Costello, M., MacRae- Krisa, L., \& Winterdyk, J. (2013). Ethnicity Diversity and youth offending: An examination of risk and protective factors. International Journal of Child, Youth and Family Shelter, 1. Retrieved from file:///C:/Users/fyiuser/Downloads/11852-7456-1$\underline{\text { PB.pdf }}$

Bishop, A. S., Hill, K. G., Gilman, A. B., Howell, J. C., Catalano, R. F., \& Hawkins, J. D. (2017). Developmental pathways of youth gang membership: A structural test of the social development model. Journal of Crime and Justice, 40(3), 275-296. doi:10.1080/0735648X.2017.1329781

Caidi, N., \& Allard, D. (2005). Social inclusion of newcomers to Canada: An information problem? Library and Information Science Research, 27(3), 302-324. doi:10.1016/j.lisr.2005.04.003

Canada. Citizenship and Immigration Canada. Evaluation. (2011). Evaluation of the immigrant settlement and adaptation program (ISAP) Citizenship and Immigration Canada = Citoyenneté et Immigration Canada. 
Chen, X., \& Zhong, H. (2013). Delinquency and crime among immigrant Youth-An integrative review of theoretical explanations. Laws, 2(3), 210-232. doi:10.3390/laws2030210

Chuang et al (2010). Chuang, S. S., \& Canadian Immigrant Settlement Sector Alliance. (2010). New start for youth study: An examination of the settlement pathways of newcomer youth Canadian Immigrant Settlement Sector Alliance.

Citizenship and Immigration Canada. (2012a). Skilled workers and professionals Available online at: http://www.cic.gc.ca/english/immigrate/skilled/index.asp

Godwin, Zainab (2017). Rising Researchers: A Newcomer Youth-led Participatory Action Research Project.

Gonsalves, T., Khanlou, N., \& Shakya, T.B. Determinants of Mental Health for Newcomer youth: Policy and Services Implications. Retrieved from: http://accessalliance.ca/wpcontent/uploads/2015/03/Determinants_of_Mental_Health for_Newcomer_YouthCdn_Issu es.pdf

Guo, S., \& Guo, Y. (2016). Immigration, integration and welcoming communities: Neighborhood-based initiative to facilitate the integration of newcomers in Calgary. Canadian Ethnic Studies, 48(3), 45-67. Retrieved from http://ezproxy.lib.ryerson.ca/login?url=http://search.proquest.com/docview/1880692337?account $\mathrm{id}=13631$ 
Jibril, S. (2011). "Cashberta": Migration Experiences of Somali- Canadian Second Generation Youth in Canada. Retrieved from:

http://vm5.library.yorku.ca/xmlui/bitstream/handle/10315/13776/SJibril_MRP.pdf?sequence=1]

Kilbride, K. M., Anisef, P., \& Canada. Citizenship and Immigration Canada. (2001). To build on hope: Overcoming the challenges facing newcomer youth at risk in Ontario Joint Centre of Excellence for Research on Immigration and Settlement.

Kilbride, K. M., Anisef, P., Baichman-Anisef, E., \& Khattar, R. (2001). Between two worlds: The experiences and concerns of immigrant youth in Ontario. Toronto, ON: Joint Centre of Excellence for Research on Immigration and Settlement (CERIS).

Lim, A., Lo, L., Siemiatycki, M., \& Doucet, M. Newcomer services in the greater Toronto area: An exploration of the range and funding sources of settlement services.

Mood, C., Jonsson, J. O., Låftman, S. B., Centrum för forskning om ojämlikhet i hälsa (CHESS), Stockholms universitet, Samhällsvetenskapliga fakulteten, \& Institutet för social forskning (SOFI). (2016). Immigrant integration and youth mental health in four European countries. European Sociological Review, 32(6), 716-729. doi:10.1093/esr/jcw027

Ngo, H.V., \& Schleifer, B. Immigrant Children and Youth in Focus. Retrieved from http://canada.metropolis.net/pdfs/Van_ngo_e.pdf 
Organisation For Economic Co-Operation, \& Development. (2015). Indicators of immigrant integration 2015 - settling in. FR: OECD Publishing.

Oxman-Martinez, J., Rummens, A. J., Moreau, J., Choi, Y. R., Beiser, M., Ogilvie, L., \& Armstrong, R. (2012). Perceived ethnic discrimination and social exclusion: Newcomer immigrant children in Canada. American Journal of Orthopsychiatry, 82(3), 376-388. doi:10.1111/j.1939-0025.2012.01161.x

Pullmann, M. D. (2010). Predictors of criminal charges for youth in public mental health during the transition to adulthood. Journal of Child and Family Studies, 19(4), 483-491. doi:10.1007/s10826-009-9320-8

Rossiter, K. \& Rossiter, M. (2009). Immigrant youth and crime Stakeholder perspectives on risk and protective factors. Retrieved from: https://sites.ualberta.ca/ pcerii/WorkingPapers/WP0209.pdf

Rossiter, M. J., Rossiter, K. R., Prairie Centre of Excellence for Research on Immigration and Integration, \& Prairie Metropolis Centre. (2009). Immigrant youth and crime: Stakeholder perspectives on risk and protective factors Prairie Metropolis Centre.

Rummens, J. A., \& Dei, G. J. (2010). Including the excluded: De-marginalizing immigrant /refugee and racialized students. Marginalized Youth: A Tranquil Invitation to a Rebellious, 50, $48-53$ 
Sadiq, K. D., \& CERIS. (2004). The two-tier settlement system: A review of current newcomer settlement services in Canada CERIS: The Ontario Metropolis Centre.

Schleifer, B., \& Ngo, H. (2005). immigrant children and youth in focus. Canadian Issues, 29.

Schmidt, C. (2010). Systemic discrimination as a barrier for immigrant teachers. Diaspora, Indigenous, and Minority Education, 4(4), 235-252. doi:10.1080/15595692.2010.513246

Sethi, B. (2015). Education and employment training supports for newcomers to Canada's middle-sized urban/rural regions: Implications for social work practice. Journal of Social Work, 15(2), 138-161. doi:10.1177/1468017313504795

Shakya, Y. B., Khanlou, N., \& Gonsalves, T. (2010). determinants of mental health for newcomer youth: Policy and service implications. Canadian Issues, , 98.

Schleifer, B., \& Ngo, H. (2005). immigrant children and youth in focus. Canadian Issues, 29.

Siantz, M. (1997). Factors that impact developmental outcomes of immigrant children. In A. Booth, A. C. Crouter, \& N. Landale (Eds.), Immigration and the family: Research and policy on U.S. immigrants (pp. 149-161). Mahwah, NJ: Erlbaum

Skokauskas, N., \& Clarke, D. (2009). Mental health of immigrant children: A new challenge for child and adolescent psychiatry services in Ireland. Child Care in Practice, 15(3), 227-233. doi:10.1080/13575270902891081 
Social Planning Council of Ottawa-Carleton. (2010). Immigrant children, youth and families: A qualitative analysis of the challenges of integration Social Planning Council of Ottawa.

The needs of newcomer youth and emerging best practices to meet those needs (2000). The Joint Centre of Research on Immigration and Settlement (CERIS).

Thomas, C. (2012). Newcomers and social inclusion in peel region, Ontario: Examining the importance of settlement services

Tolle, H. (2017). Gang affiliation as a measure of social structure in social structure social learning theory. Deviant Behavior, 38(8), 870-878. doi:10.1080/01639625.2016.1206712

Verkuyten, M. (2003). Positive and negative self-esteem among ethnic minority early adolescents: Social and cultural sources and threats. Journal of Youth and Adolescence, 32, 267277.

Wang, S., \& Truelove, M. (2003). Evaluation of settlement service programs for newcomers in Ontario: A geographical perspective. Journal of International Migration and Integration / Revue De l'Integration Et De La Migration Internationale, 4(4), 577-606. Doi:10.1007/s12134-003$1015-1$

Wong, C. A., Eccles, J. S., \& Sameroff, A. (2003). The influence of ethnic discrimination and ethnic identification on African American adolescents' school and socioemotional adjustment. Journal of Personality, 71, 1198-1232. 
Wortley, S. (2009). Introduction. the immigration-crime connection: Competing theoretical perspectives. Journal of International Migration and Integration, 10(4), 349-358.

doi:http://dx.doi.org.ezproxy.lib.ryerson.ca/10.1007/s12134-009-0117-9

Wortley, S., \& Owusu- Bempah, A. (2009). Unequal Before the Law: Immigrant and Racial Minority perceptions of the Canadian Criminal Justice System. Int. Migration and Integration, 10. Retrieved from file:///C:/Users/fyiuser/Downloads/Wortley_and_OwusuBempah 2009_Unequal_Before the Law-libre.pdf

Wortley, S., \& Tanner, J. (2004). Discrimination or "Good” policing? The Racial Profiling Debate in Canada. Retrieved from: http://canada.metropolis.net/researchpolicy/cities/publication/diverse_cite_magazine_e.pdf\#page $=198$ 